\title{
Protective Effect of Natrium Diethyldithiocarbamate Trihydrate (NDDCT) on Lead Induced Neurodegeneration in Rats
}

\author{
Sudhir Kumar ${ }^{1,2}$, Harikesh Maurya ${ }^{1,3}$, Sandeep $^{4}$, Saikat Sen ${ }^{5}$, Raja Chakraborty ${ }^{6, *}$ \\ ${ }^{1}$ Department of Pharmacology, Hygia Institute of Pharmaceutical Education and Research, Lucknow, Uttar Pradesh, INDIA. \\ ${ }^{2}$ Department of Pharmacology, JS Singh Institute of Pharmacy, Dhondhi-Parasarai, Uttar Pradesh, INDIA. \\ ${ }^{3}$ Department of Pharmacology, MGB Rajat College of Pharmacy and Management, Ambedkarnagar, Uttar Pradesh, INDIA. \\ ${ }^{4}$ Department of Pharmacognosy Praduman Singh Shikshan Prashikshan Sansthan Pharmacy College, Basti, Uttar Pradesh, INDIA. \\ ${ }^{5}$ Faculty of Pharmaceutical Science, Assam Down Town University, Guwahati, Assam, INDIA. \\ ${ }^{6}$ Department of Pharmaceutical Chemistry, NEF College of Pharmacy, Guwahati, Assam, INDIA.
}

\begin{abstract}
Aim: Lead is a powerful metal which induced neurotoxicity through the degradation of neurons in the body. Various neuronal changes have shown correlation with the generation of free radicals and oxidative stress. The present study was carried out to evaluate the neuroprotective activity of Natrium diethyl dithiocarbamate trihydrate (NDDCT) on lead induced neurodegeneration in rat's model. Methods: We have evaluated the neuroprotective activity of NDDCT using Morris Water maze, Elevated plus maze, Photoactometer and Hebb's William maze models and also evaluated different biochemical parameters. Neurodegeneration was induced by administering lead acetate $(1 \mathrm{mg} / \mathrm{kg} / \mathrm{day})$ for 35 days. Test drug NDDCT $(5 \mathrm{mg} / \mathrm{kg}$ and $10 \mathrm{mg} / \mathrm{kg}$ ) and standard drug donepezil were also administered concurrently in test and standard drug treated group. Results: NDDCT found to improve escape latency time (in Morris Water Maze), transfer latency time (in Elevated plus Maze), time to reach reward chamber (Hebb William's Maze) and locomotor activity. The neuroprotective activity of NDDCT was confirmed by evaluation of in vivo antioxidant and estimation of other biochemical parameters. NDDCT found to improve the level of reduced glutathione, catalase, superoxide dismutase, sodium nitrate and reduced the level of serum lead, TNF- $\alpha$, nitric oxide, acetylcholinesterase enzyme in the test group when compared with the disease control group. Histopathological evaluation of the brain also confirms the protective effect of NDDCT. Conclusion: These results suggest that NDDCT can be used as a preventive drug against lead-induced neurodegeneration, cholinergic dysfunctions and oxidative stress.
\end{abstract}

Key words: Natrium diethyldithiocarbamate trihydrate (NDDCT), Neuroprotective, Biomarkers, Physical activity, Neurodegeneration, Cholinergic dysfunction.

Key Messages: Natrium diethyldithiocarbamate trihydrate found effective to prevent against lead-induced neurodegeneration, cholinergic dysfunctions and oxidative stress.

\section{INTRODUCTION}

Neurodegenerative disease is a critical state of failure of formation of the nerve induction and impulse within the human brain. ${ }^{1}$ The main pathological mechanism is the deposition and aggregation of misfolded proteins within the brain causes a progressive loss of neurons that result in neurodegenerative disorders. ${ }^{2}$ Environmental factors, ageing and even genetic predisposition are the most common factors that effects mostly aged patients. The neurodegenerative diseases are incurable, however progression illness curable. $^{3}$

Lead is one of the most significant environmental pollutants and considers as a neurotoxin. Lead exposure is considered unavoidable, as it found in or deriving
Submission Date: 07-01-2020; Revision Date: 22-06-2020; Accepted Date: 16-12-2020

DOI: 10.5530/ijper.55.1.15 Correspondence: Dr. Raja Chakraborty Professor and Principal, NEF College of Pharmacy, Lokhra, Guwahati-781040, Assam, INDIA.

Phone: +919401170374

E-mail: dr_rchakraborty@ rediffmail.com

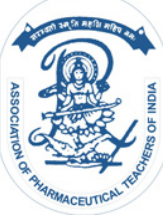

www.ijper.org 
from different colours, coloured inks, paints, lacquers, ceramics, cosmetics, hair dye, coating materials, toys, gasoline, batteries, water pipes, solders, different types of equipment used in farm, shielding for X-ray machines etc. ${ }^{4,5}$ Lead is extensively distributed in the human body. Acute or chronic exposure of lead is may interfere with biochemical processes and contributing to oxidative stress, lungs diseases, gastrointestinal and nephritic disorder, cancer, neurotoxicity etc. ${ }^{4}$ Exposure to lead may cause impairment of learning, behaviour, cognitive function and hearing. ${ }^{4,5} \mathrm{~A}$ number of probable theories were studied but no specific mechanisms have been yet defined that can explain lead-induced neurotoxicity accurately. ${ }^{5}$ Though, lead is known for impairing calcium ion signalling, modification of neurotransmitters release, oxidative stress, interference with energy metabolism, alteration of cellular and metabolic functions, disruption of dopaminergic, GABAergic and cholinergic system. Lead toxicity results alteration of intelligence, executive functioning, memory, attention, language, mood, visuospatial and motor skills. ${ }^{5}$

Sodium diethyldithiocarbamate trihydrate is a key disulfiram metabolite that also acts as a chelating agent. A number of therapeutic importance of sodium diethyldithiocarbamate trihydrate were identified which includes, metal (i.e. $\mathrm{Ni}$, Th, $\mathrm{Cd}, \mathrm{Zn}, \mathrm{Cu}, \mathrm{Co}, \mathrm{Hg}, \mathrm{Pb}$ ) chelating activity in case of metal poisoning, treatment of hepatolenticular degradation and systemic lupus erythematosus, antidote of polyhalogen compounds (i.e. $\mathrm{CHCl}_{3}, \mathrm{CCl}_{4}, \mathrm{BrClF}_{3}$ ) poisoning, as an adjunct during cisplatin treatment, protective against in case of radiation sensitization, fungal infection inhibition, inhibitor of AIDS and AIDS-related complex progression, immunomodulator etc. ${ }^{6}$ Natriumdiethyl dithiocarbamate tetrahydrate (NDDCT) is an inhibitor of nuclear factor kappa-B (NF- $x \mathrm{~B})$ and a recent study found that NDDCT treatment positively attenuated deoxycorticosterone acetate hypertension-induced dysfunction of endothelial, memory impairment and learning impairment. ${ }^{7}$

Considering mentioned literature, this study designed to find the protective effect of NDDCT against neurodegeneration induced by lead in experimental rats.

\section{MATERIALS AND METHODS}

Experimental animals: Wistar rats (body weight 180 $\pm 20 \mathrm{~g}$; either sex) were used for this study. Rats were kept in appropriate environmental condition for seven days for acclimatization. Animals were fed with standard pellet diet and water ad libitum. All the experimental protocol was approved by the Institutional Animal Ethical Committee of HIPER, Lucknow (Approval no. HIPER/IAEC/12/18/04).

Drugs and chemicals: Natrium diethyldithiocarbamate trihydrate (NDDCT), donepezil and lead acetate were purchased from AviChem Industries, Mumbai. All other drugs, chemical/laboratory reagents used in the study were the analytical grades, procured from local suppliers.

Experimental design: Healthy animals were divided into different groups $(n=6)$ as mentioned and the effect of NDDCT was evaluated through different studies.

Group I: Normal control (administered 0.9\% normal saline) Group II: Vehicle control (administered distilled water)

Group III: Disease control [administered lead acetate $(1 \mathrm{mg} / \mathrm{kg} /$ day $)]$

Group IV: NDDCT - 5 [Lead acetate $(1 \mathrm{mg} / \mathrm{kg} /$ day $)$

$+\operatorname{NDDCT}(5 \mathrm{mg} / \mathrm{kg} /$ day $)]$

Group V: NDDCT - 10 [Lead acetate $(1 \mathrm{mg} / \mathrm{kg} /$ day $)+$ NDDCT $(10 \mathrm{mg} / \mathrm{kg} /$ day)]

Group VI: Standard drug [Lead acetate $(1 \mathrm{mg} / \mathrm{kg} /$ day $)$ + Donepezil $(0.5 \mathrm{mg} / \mathrm{kg} /$ day $)]$

All the drugs were administered by oral route every day for 35 days. NDDCT and donepezil and lead acetate were prepared freshly by dissolving in normal saline and administered orally. During the study period assessment of learning and memory and gross behavioral activity was performed on a different day of the study period. After the study period, animals were sacrificed and assessment of biochemical parameters, antioxidant activity was carried out.

\section{Evaluation of memory, learning and anxiety}

Morris water maze (MWM): It was observed that rodents do not like swimming and they want to come out by finding hidden escape stage when retained them in water pool. All the animals were subjected to 04 repeated searching trials (5 min interval between each trial) for each day and this this study was carried out for consecutive 4 days $\left(31^{\text {st }}\right.$ to $34^{\text {th }}$ day). During this study, escape latency time (ELT) considered as learning index which was calculated as the time required to find the hidden stage. ${ }^{8}$

Elevated plus maze (EPM): EPM is used as a behavioral model to find the effect of the drug on anxiety in experimental animals using standard elevated maze apparatus. EPM study was carried out for two days $\left(33^{\text {rd }}\right.$ and $34^{\text {th }}$ day of the scheduled protocol). Transfer Latency (TL), was explained by the time taken by each experimental rat to enter fully into any one of close arms that recorded on the $33^{\text {rd }}$ day, i.e., acquisition trial. In case animal fails to move into any close arms 
within 120 s, then animals were softly pushed into any one of close arm and TL was recorded as 120s. TL was evaluated $24 \mathrm{hr}$ after the first trial on the $34^{\text {th }}$ day (retention latency).., 10

Hebb William's maze: It is an incentive-based model of exteroceptive behavioral study that used to measure spatial and working memory of rats. Hebb William's maze consists of animal chamber (i.e. start box), middle chamber (i.e. exploratory part) and reward (i.e. food) chamber. On the $24^{\text {th }}$ day of the study, all the rats were familiarized with the Hebb William maze for $2 \mathrm{~min}$. Till $28^{\text {th }}$ day the rats provide four regular training trials per day into the maze. In every trial, the animal placed into the start box and the timer was started as soon as the rats left the chamber. Time taken by animals to find the award chamber was considered as the learning score of the trial. The mean of 4 trials was recorded as the learning score (TRC) for that day. Efficient learning was indicated by the lower score during assessment while higher scores point out towards poor learning in rats. A fall in time for subsequent maze exposure is an index of successful retention. The animals were deprived of food during the assessment period and water was given after $1 \mathrm{hr}$ of maze exposure to make sure motivation towards the reward area. ${ }^{11,12}$

Gross behavioral activity using Actophotometer: Gross behavioral movement was evaluated by actophotometer on the $1^{\text {st }}$ and $34^{\text {th }}$ day of scheduled study. These days were selected to avoid any intrusion in locomotors activity that may alter memory and learning behavior observed in MWM task. Locomotors activity is the score for five minutes when each rat kept in actophotometer. ${ }^{13}$

\section{Assessment of biochemical parameter and antioxidant activity}

Collection of blood sample: On the $35^{\text {th }}$ day of scheduled protocol after respective drug treatment, blood was collected by the retro-orbital process and were kept for the $30 \mathrm{~min}$. Serum was separated after centrifugation at 4,000 $\mathrm{rpm}$ for $15 \mathrm{~min}$, which was used to estimate nitrite, lead and TNF- $\alpha .{ }^{7}$

Preparation of brain homogenate: After blood collection, all rats were sacrificed and brain tissue was removed and homogenized using ice-cold $0.1 \mathrm{M}$ phosphate buffer ( $\mathrm{pH}$ 7.4). Homogenates thus obtained were centrifuged at $10,000 \times \mathrm{g}$ for $15 \mathrm{~min}$ to get supernatant that was used for estimations of acetylcholinesterase, nitric oxide and antioxidant parameters. ${ }^{14}$

Estimation of serum nitrite, lead and TNF- $\alpha$ concentration: Serum nitrite level was estimated spectrophotometrically at $545 \mathrm{~nm}$ adopting a standard protocol. ${ }^{15}$ Levels of lead in serum were measured at $217 \mathrm{~nm}$ wavelengths using a spectrophotometer (AAS 4129, Electronic Corporation of India Limited) and $6 \mathrm{MA}$ current. The values were expressed in ppm. ${ }^{16,17}$ Level of serum TNF- $\alpha$ was estimated using a standard typical "sandwich type" immunoassay. Fluorescence measurements were performed in a Perkin Elmer M 512-A fluorescence spectrophotometer as per standard protocol. ${ }^{18}$

Estimation of acetylcholinesterase (AChE) enzyme: Acetylcholinesterase (AChE) activity was estimated using the method of Ellman et al. AChE activity (whole brain) was noted as nmol per mg protein. ${ }^{19}$

Assessment of nitric oxide (NO): NO in brain was accessed as total nitrate/nitrite using Griess reagent, ${ }^{20}$ and represented as $\mu \mathrm{mol} / \mathrm{g}$ wet tissue. A chromophore was formed by the diazotization of sulfanilamine (present in Griess reagent) by acetic nitrite followed by $\mathrm{N}$-(1-naphthyl) ethylenediamine coupling. An azo derivative (coloured) thus formed can be estimated at $540 \mathrm{~nm}$ spectrophotometrically. ${ }^{21}$

Estimation of enzymatic and non-enzymatic antioxidant enzyme: Superoxide dismutase (SOD) activity was estimated as per the standard protocol of Misra and Frodvich. ${ }^{22}$ Catalase (CAT) activity was estimated as per the standard protocol of Aebi. ${ }^{23}$ Level of reduced glutathione (GSH) in brain tissue was determined spectrophotometrically at $412 \mathrm{~nm}$ using a standard method. ${ }^{13,24}$

Determination of malondialdehyde (MDA): Determination of MDA, the end product of lipid peroxidation was carried out as per the method of Wills. ${ }^{17}$ Level of MDA in brain tissue was expressed as $\mathrm{nmol} / \mathrm{mg}$ protein.

Thiobarbituric acid reactive substances (TBARS) estimation: TBARS was estimated at $532 \mathrm{~nm}$ using the method of Ohkawa et al. ${ }^{13,25}$

\section{Histopathological study of the brain tissues}

Brains were removed quickly after sacrificing the animals and kept in 10\% formaldehyde. Brain sections were stained with hematoxylin and eosin (H\&E) and checked microscopically. ${ }^{26}$

\section{Statistical analysis}

Values were expressed as the mean \pm S.E.M. $(n=6)$. Statistical analysis was completed by one way ANOVA followed by Bonferroni-compare method. ${ }^{*} p<0.05$ considered as statistically significant in comparison to normal and vehicle control, while ${ }^{* *} p<0.05$ considered 
as statistically significant in comparison with the disease control group.

\section{RESULTS}

\section{Effect of NDDCT on memory and learning}

Activity on MWM: On $31^{\text {st }}$ day and $34^{\text {th }}$ day of the entire study protocol, ELT of experimental rats were observed and recorded (Figure 1). Result showed that after lead administration there is significant $\left({ }^{\#} p<0.05\right)$ increase in ELT on the $1^{\text {st }}$ day $(66.67 \pm 23.62$ sec) compared to normal and vehicle control group. Treatment with NDDCT (low dose) showed significant $\left({ }^{* *} p<0.05\right)$ reduction of ELT on $1^{\text {st }}$ day $(30.67 \pm 11.81 \mathrm{sec})$ and after 3 days acquisition trial ( $4^{\text {th }}$ day).

Activity on Elevated plus Maze: TL of experimental rats were observed and recorded in Figure 2. Result showed that, after lead acetate oral administration TL significantly $\left({ }^{*} p<0.05\right)$ elevated on $34^{\text {th }}$ day $(78.50 \pm 4.42$ sec in close arm) and $(8.17 \pm 2.79 \mathrm{sec})$ compared to normal control. In case of low dose of NDDCT there is significant $\left({ }^{* *} p<0.05\right)$ reduction of anxiety as TL recorded $56.17 \pm 12.28 \mathrm{sec}$ (in close arm) and $26.67 \pm 11.05 \mathrm{sec}$ (in open arm). Though, in case of NDDCT high dose and standard treatment group there is little reduction of anxiety.

Activity on Hebb William's Maze: On the $24^{\text {th }}$ and $28^{\text {th }}$ day, the behavioral activity of experimental rats was observed and recorded in Figure 3. After oral administration of lead acetate in rats there was significance changes $\left({ }^{\#} p<0.05\right)$ in behavioral activity as compared to the normal control group, but on $28^{\text {th }}$ day lead acetate administered group did not show significantly $\quad\left({ }^{\#} p<0.05\right) \quad$ improvement $(154.29 \pm 44.13)$

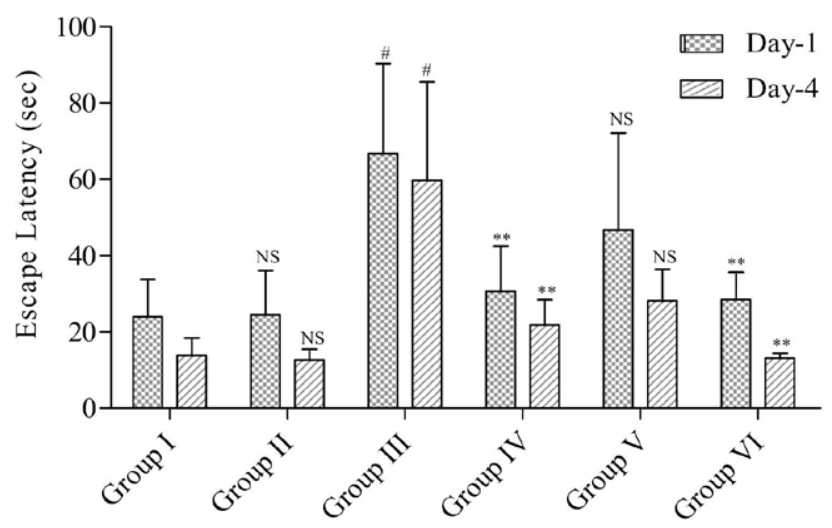

Figure 1: Effect of NDDCT on escape latency time of rats on $1^{\text {st }}$ and $4^{\text {th }}$ day using Morris Water Maze. Values are given as Mean \pm SEM of experimental animals $(n=6)$; NS= Nonsignificance; $\# p<0.05$ - Represents statistical significance against Normal Control, ${ }^{* *} p<0.05$-Represents statistical significance against Disease Control behavioral effect when compared to the normal control group. Low dose of NDDCT showed significant improvement $\left({ }^{\#} p<0.05\right)$ in behavioral activity on $28^{\text {th }}$ day (36.21 \pm 20.03$)$. Though, in case of NDDCT high dose and standard treatment groups showed a little betterment of increased elevated TRC compared to disease control animal.

Effect of NDDCT on Locomotor activity using Actophotometer: On the $1^{\text {st }}$ day and $34^{\text {th }}$ day of 35 days study protocol locomotor activity was recorded. Locomotor activity of experimental rats was observed and recorded in Figure 4. Result showed that, after oral administration of lead acetate there is no significant changes $\left({ }^{\#} p<0.05\right)$ in locomotor activity compared to normal control group, but at end of the study disease control group showed significant $\left({ }^{\#} p<0.05\right)$ decrease $(298.50 \pm 34.32)$ in locomotor activity compare to normal control rats $(430.50 \pm 37.06)$, NDDCT low dose with showed significant $\left({ }^{* *} p<0.05\right)$ improvement in

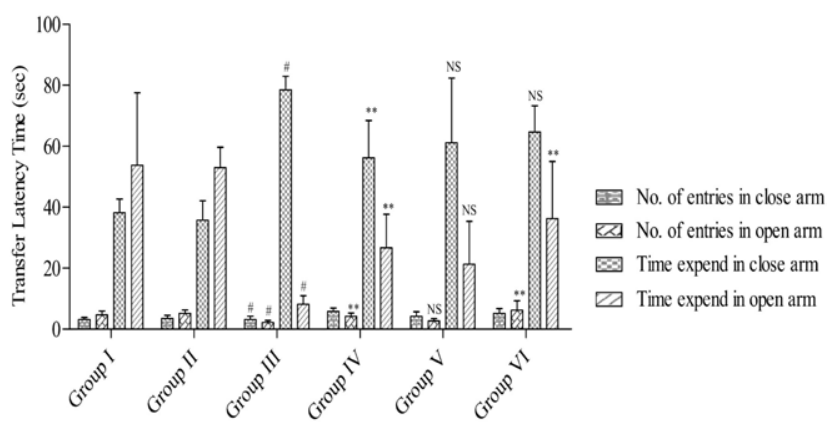

Figure 2: Effect of NDDCT on transfer latency time (TL) of rats using Elevated Plus Maze. Values are given as Mean \pm SEM of experimental animals $(n=6) ; N S=$ Non-significance. $\# p<0.05$ -Represents statistical significance against Normal Control, ${ }^{* *} p<0.05-R e p r e s e n t s$ statistical significance against Disease Control.

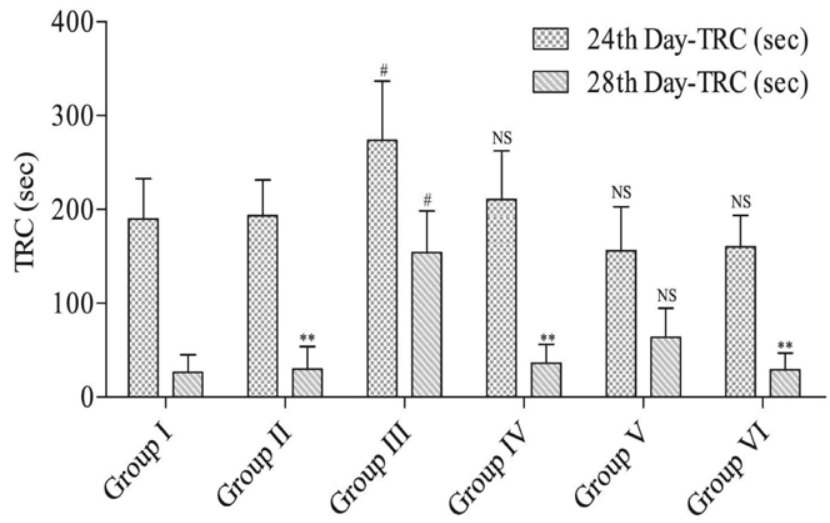

Figure 3: Effect of NDDCT on time to reach Reward Chamber (TRC) of rats using Hebb William's Maze. Values are given as Mean \pm SEM of experimental animals $(n=6)$; NS $=$ Nonsignificance. \#P<0.05 -Represents statistical significance against Normal Control, ${ }^{* *} P<0.05$ Represents statistical significance against Disease Control. 
locomotor activity (419.67 \pm 38.95$)$. NDDCT high dose showed little and standard treatment group showed significant $\quad\left({ }^{* *} p<0.05\right)$ improvement of locomotor activity.

\section{Effect of NDDCT biochemical and antioxidant parameter}

Serum nitrite and lead concentration: The concentration of serum nitrite and serum lead in the blood of experimental rats were observed and recorded in Table 1. After oral administration of lead acetate in rats, there was a significant $\left({ }^{\#} p<0.05\right)$ decrease in serum nitrite concentration $(6.36 \pm 2.18 \mu \mathrm{mol} / \mathrm{l})$ but increase in serum lead concentration (85.32 \pm 8.31$)$ in comparison to the normal control group, i.e. $(12.69 \pm 4.17 \mu \mathrm{mol} / \mathrm{l})$ and $(13.19 \pm 3.12 \mu \mathrm{g} / \mathrm{dl})$. In case of NDDCT low dose there was significant $\left({ }^{* *} p<0.05\right)$ improvement in serum nitrite concentration $(12.46 \pm 3.23 \mu \mathrm{mol} / \mathrm{l})$ and reduction in serum lead concentration $(17.18 \pm 3.33 \mu \mathrm{g} / \mathrm{dl})$. Though, in case of high dose of NDDCT and standard treatment group showed a little significance $\left({ }^{* *} p<0.05\right)$ improvement of nitrite and lead concentration to disease control animal. Rats treated with NDDCT low

\begin{tabular}{|c|c|c|c|}
\multicolumn{4}{|c|}{ Table 1: Effect of NDDCT on serum nitrite and lead } \\
concentration. \\
\hline $\begin{array}{c}\text { Group } \\
\text { No }\end{array}$ & Groups & $\begin{array}{c}\text { Serum nitrite } \\
\text { conc. }(\boldsymbol{\mu m o l} / \mathrm{L})\end{array}$ & $\begin{array}{c}\text { Serum lead } \\
\text { conc. }(\boldsymbol{\mu g} / \mathrm{dl})\end{array}$ \\
\hline I & $\begin{array}{c}\text { Normal } \\
\text { Control }\end{array}$ & $12.69 \pm 4.17$ & $13.19 \pm 3.12$ \\
\hline II & $\begin{array}{c}\text { Vehicle } \\
\text { Control }\end{array}$ & $11.95 \pm 3.55^{\text {NS }}$ & $13.92 \pm 4.24^{\text {NS }}$ \\
\hline III & $\begin{array}{c}\text { Disease } \\
\text { group }\end{array}$ & $6.36 \pm 2.18^{\#}$ & $85.32 \pm 8.31^{\#}$ \\
\hline IV & NDDCT-5 & $12.46 \pm 3.23^{* *}$ & $17.18 \pm 3.33^{* *}$ \\
\hline V & NDDCT-10 & $11.75 \pm 3.48^{* *}$ & $18.45 \pm 3.22^{\text {NS }}$ \\
\hline VI & $\begin{array}{c}\text { Standard } \\
\text { group }\end{array}$ & $11.78 \pm 3.48^{* *}$ & $12.60 \pm 3.2^{* *}$ \\
\hline
\end{tabular}

Values are given as Mean \pm SEM of experimental animals $(n=6)$; NS= Nonsignificance. ${ }^{\sharp} P<0.05$-Represents statistical significance against Normal Control, ${ }^{* *} P<0.05$-Represents statistical significance against Disease Control

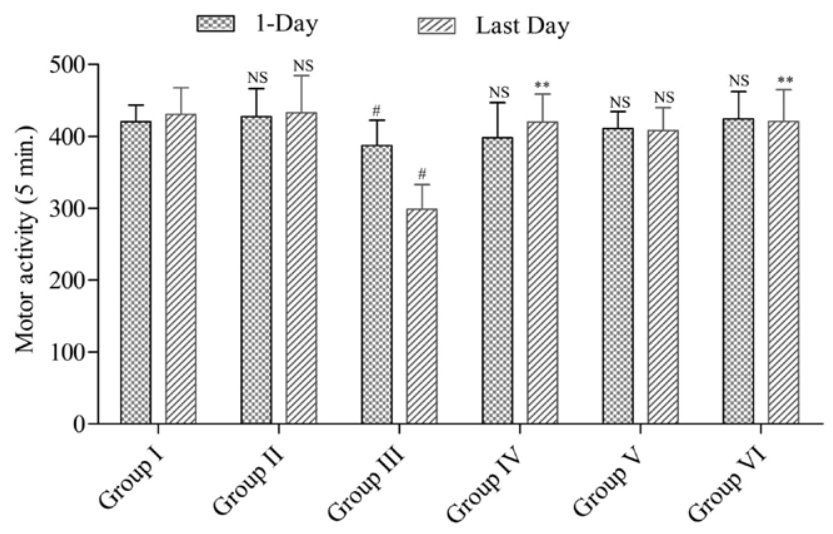

Figure 4: Effect of NDDCT on locomotion activity of rats using Photoactometer. Values are given as Mean \pm SEM of experimental animals $(n=6)$; NS= Non-significance. $\# P<0.05$ Represents statistical significance against Normal Control, ** $P<0.05$-Represents statistical significance against Disease Control.

dose showed higher activation or inhibition of these parameters.

Serum TNF- $\alpha$ level: The level of TNF- $\alpha$ in the blood of experimental rats was observed and recorded in Figure 5. Lead acetate administration resulted significant $\left({ }^{\#} p<0.05\right)$ increase in serum TNF- $\alpha(0.00355 \pm 0.00146$ $\mathrm{ng} / \mathrm{ml}$ ) in comparison to normal control group $(0.00249 \pm 0.00127 \mathrm{ng} / \mathrm{ml})$. Rat treated with low dose of NDDCT cause significant $\left({ }^{* *} p<0.05\right)$ decrease in the level of TNF- $\alpha(0.00258 \pm 0.00133 \mathrm{ng} / \mathrm{ml})$. Rats treated with high dose of NDDCT or standard treatment showed a little significant $\left({ }^{* *} p<0.05\right)$ or non-significance reduction of TNF- $\alpha$ compare to disease control animal. Effect of NDDCT on endogenous antioxidants: The concentration of SOD, CAT and GSH in brain homogenate of experimental rats were observed and recorded in Table 2. Result showed that after oral administration of lead acetate in rats there was significant $\left({ }^{\#} p<0.05\right)$ decreases the antioxidant levels such as SOD $(447.27 \pm 22.97 \mathrm{U} / \mathrm{g}$ protein), CAT $(102.87 \pm 5.63$ $\mu \mathrm{g} / \mathrm{g}$ protein) and $\mathrm{GSH}(7.28 \pm 2.37 \mu \mathrm{M} / \mathrm{mg}$ protein) in comparison to the normal control group. Level of

\section{Table 2: Effect of NDDCT on endogenous antioxidants.}

\begin{tabular}{|c|c|c|c|c|}
\multicolumn{5}{|c|}{ Table 2: Effect of NDDCT on endogenous antioxidants. } \\
\hline \multirow{2}{*}{ Group No } & Groups & $\begin{array}{c}\text { SOD } \\
(\text { U/g protein) }\end{array}$ & $\begin{array}{c}\text { CAT } \\
(\boldsymbol{\mu g} / \mathbf{g} \text { protein })\end{array}$ & $\begin{array}{c}\text { GSH } \\
(\boldsymbol{\mu} \text { M/mg protein })\end{array}$ \\
\hline I & Normal Control & $626.39 \pm 21.24$ & $126.10 \pm 6.15$ & $18.26 \pm 3.05$ \\
\hline II & Vehicle Control & $620.67 \pm 18.28^{\mathrm{NS}}$ & $124.30 \pm 7.39^{\mathrm{NS}}$ & $17.85 \pm 3.34^{\mathrm{NS}}$ \\
\hline III & Disease group & $447.27 \pm 22.97^{\#}$ & $102.87 \pm 5.63^{\#}$ & $7.28 \pm 2.37^{\#}$ \\
\hline IV & NDDCT-5 & $624.32 \pm 24.90^{* *}$ & $114.30 \pm 7.71^{* *}$ & $18.10 \pm 3.17^{* *}$ \\
\hline V & NDDCT-10 & $538.01 \pm 25.25^{\mathrm{NS}}$ & $112.16 \pm 6.64^{\mathrm{NS}}$ & $16.87 \pm 3.24^{\mathrm{NS}}$ \\
\hline VI & Standard group & $617.51 \pm 27.33^{* *}$ & $125.95 \pm 8.38^{* *}$ & $17.91 \pm 3.28^{* *}$ \\
\hline
\end{tabular}

Values are given as Mean \pm SEM of experimental animals $(n=6)$; NS= Non significance.

${ }^{\#} p<0.05$-Represents statistical significance against Normal Control, $* * p<0.05$-Represents statistical significance against Disease Control 


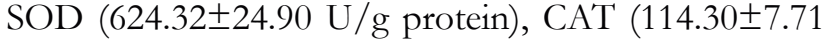
$\mu \mathrm{g} / \mathrm{g}$ protein) and GSH $(18.10 \pm 3.17 \mu \mathrm{M} / \mathrm{mg}$ protein) increased in rat treated with low dose of NDDCT. Standard group showed significant enhancement of endogenous antioxidants level while high dose of NDDCT group exhibited non-significant enhancement of endogenous antioxidants level.

Effect of NDDCT on MDA and TBARS: The concentration of MDA and TBARs in brain homogenate of experimental rats were observed and recorded in Table 3. Oral administration of lead acetate in rats significantly $\left({ }^{\#} p<0.05\right)$ increase the level of MDA (42.89 $\pm 6.193 \mathrm{nM} / \mathrm{mg}$ protein) and TBARs $(11.13 \pm 2.07 \mathrm{nM} / \mathrm{mg}$ protein) in comparison to the normal control group or vehicle control. Low dose of NDDCT showed significant $\left({ }^{* *} p<0.05\right)$ reduction in MDA level $(27.86 \pm 3.15 \mathrm{nM} / \mathrm{mg}$ protein) and TBARS level $(4.82 \pm 1.50 \mathrm{nM} / \mathrm{mg}$ protein).

Effect of NDDCT on NO and AChE: Concentration of $\mathrm{NO}$ and $\mathrm{AChE}$ in brain homogenate of experimental rats were observed and recorded in Table 4. Result

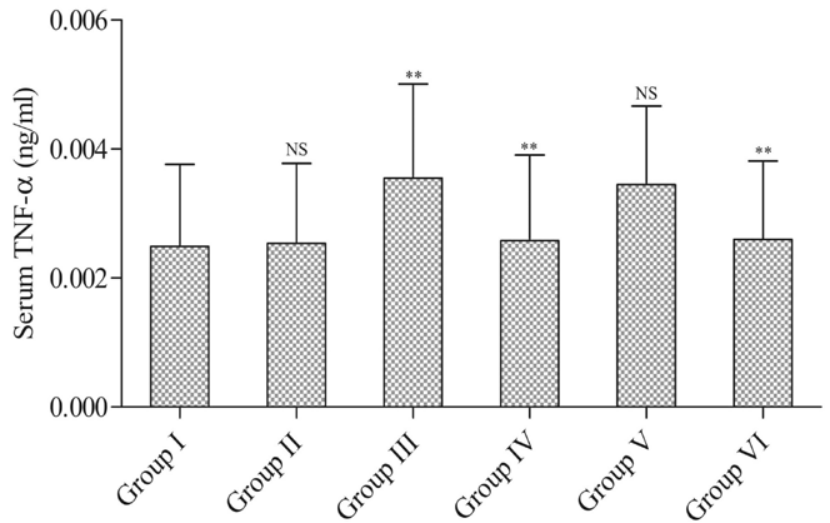

Figure 5: Effect of NDDCT on serum TNF- $\alpha$. Values are given as Mean \pm SEM of experimental animals $(n=6)$; NS=Non significance. $\# P<0.05$-Represents statistical significance against Normal Control, ${ }^{*} P<0.05$-Represents statistical significance against Disease Control.

\section{Table 3:Effect of NDDCT on MDA and TBARS.}

\begin{tabular}{|c|c|c|c|}
\hline $\begin{array}{c}\text { Group } \\
\text { No }\end{array}$ & Groups & $\begin{array}{c}\text { MDA (nM/mg } \\
\text { protein) }\end{array}$ & $\begin{array}{c}\text { TBARS (nM/ } \\
\text { mg protein) }\end{array}$ \\
\hline I & Normal Control & $19.38 \pm 4.33$ & $4.78 \pm 1.77$ \\
\hline II & Vehicle Control & $19.27 \pm 3.88^{\mathrm{NS}}$ & $4.08 \pm 1.51^{\mathrm{NS}}$ \\
\hline III & Disease group & $42.89 \pm 6.193^{\#}$ & $11.13 \pm 2.07^{\#}$ \\
\hline IV & NDDCT-5 & $27.86 \pm 3.15^{* *}$ & $4.82 \pm 1.50^{* *}$ \\
\hline V & NDDCT-10 & $33.64 \pm 3.26^{\mathrm{NS}}$ & $4.22 \pm 1.67^{* *}$ \\
\hline VI & Standard group & $23.42 \pm 3.43^{* *}$ & $4.65 \pm 1.65^{* *}$ \\
\hline
\end{tabular}

Values are given as Mean \pm SEM of experimental animals $(n=6)$; NS= Non significance. $\# p<0.05$-Represents statistical significance against Normal Control, $* * p<0.05$-Represents statistical significance against Disease Control showed that, oral administration of lead acetate in rats significantly $\left({ }^{\#} p<0.05\right)$ increased the level of $\mathrm{NO}$ and AChE in comparison to the normal control group. Treatment with NDDCT (high and low dose) produced significant $\left({ }^{* *} p<0.05\right)$ reduction of $\mathrm{NO}$ and AChE.

\section{Histopathology}

Figure 6 represents histopathological observation of the brain of various groups. Panels (A) and (B) show

\section{Table 4:Effect of NDDCT on NO and AChE.}

\begin{tabular}{|c|c|c|c|}
\hline $\begin{array}{c}\text { Group } \\
\text { No }\end{array}$ & Groups & $\begin{array}{c}\text { NO }(\boldsymbol{\mu m o l} / \mathbf{g} \\
\text { protein) }\end{array}$ & $\begin{array}{c}\text { AchE activity } \\
(\boldsymbol{\mu} \mathrm{M} / \mathrm{mg} \\
\text { protein) }\end{array}$ \\
\hline I & $\begin{array}{c}\text { Normal } \\
\text { Control }\end{array}$ & $75.73 \pm 5.19$ & $3.73 \pm 1.70$ \\
\hline II & $\begin{array}{c}\text { Vehicle } \\
\text { Control }\end{array}$ & $74.74 \pm 5.26^{\mathrm{NS}}$ & $3.86 \pm 1.63$ \\
\hline III & Disease group & $110.80 \pm 6.48^{\#}$ & $10.71 \pm 2.74^{\#}$ \\
\hline IV & NDDCT-5 & $80.39 \pm 6.37^{* *}$ & $4.43 \pm 1.84^{* *}$ \\
\hline V & NDDCT-10 & $78.36 \pm 5.38^{* *}$ & $3.96 \pm 1.36^{* *}$ \\
\hline VI & $\begin{array}{c}\text { Standard } \\
\text { group }\end{array}$ & $68.91 \pm 5.37^{* *}$ & $3.82 \pm 1.29^{* *}$ \\
\hline
\end{tabular}

Values are given as mean \pm SEM of experimental animals $(n=6) ; \mathrm{NS}=$ Non significance.\#p< 0.05 -Represents statistical significance against Normal Control, $* * p<0.05$-Represents statistical significance against Disease Control.

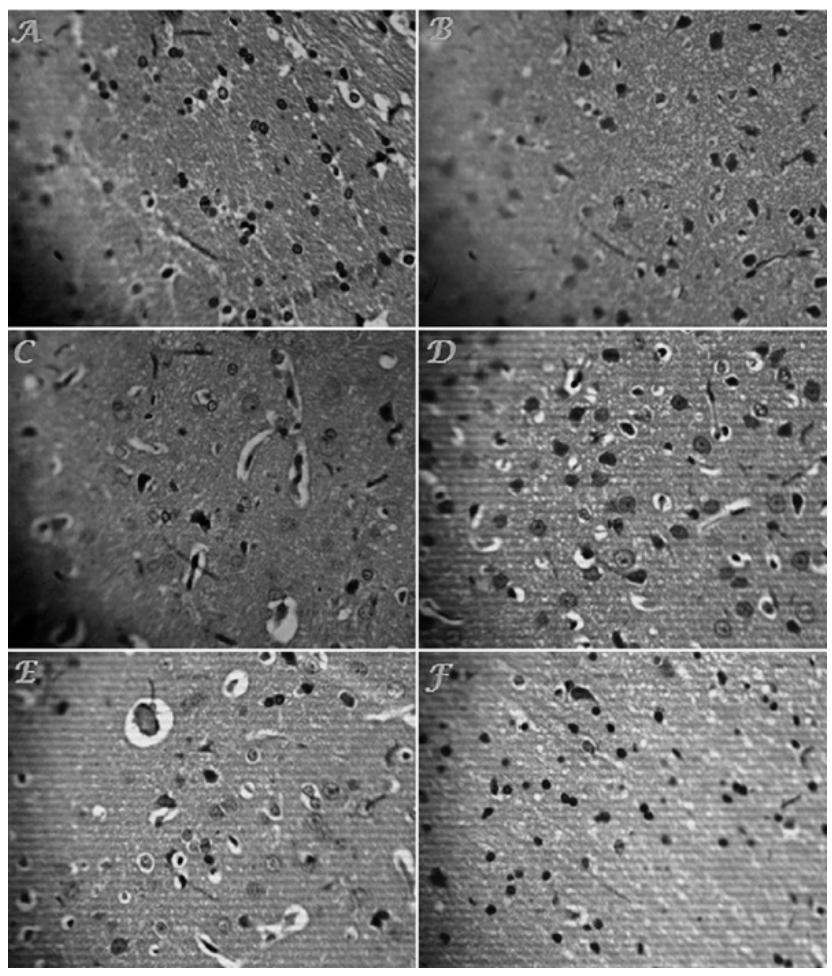

Figure 6: Histopathological evaluation of the brain. All slides were stained with hematoxylin and eosin and are shown at a magnification of 40x. (A) normal control; (B) vehicle control;

(C) disease control; (D) NDDCT - 5; (E) NDDCT - 10, (F) Standard drug. 
brain sections of normal control and vehicle control rats respectively which showed that there were no alterations in the histopathology of the brain of control groups. Brain sections from the disease control group (panel C) showed infected vessels and leukocytes adhered to the endothelium. On 40x, there were diffuse inflammatory cells and intense hemorrhagic foci in group IV rats (panel D) in which minor improvement observed in mild hemorrhagic foci with leukocytes adhered to endothelium in NDDCT $(5 \mathrm{mg} / \mathrm{kg})$ treated rat. In Panel E (NDDCT - 10mg/kg group) improvement observed as mild hemorrhagic foci with leukocytes adhered to endothelium was observed. In standard drug-treated group (Panel F) very little alterations in mild hemorrhagic foci with leukocytes adhered to endothelium were observed.

\section{DISCUSSION}

Neurodegenerative disease is considered as an agedepended disorder that results from the progressive loss of neurons from the brain. Major Neurodegenerative diseases include Alzheimer's Disease (AD), Parkinson's Disease (PD), amyotrophic lateral sclerosis. $\mathrm{AD}$ is characterized by loss of memory, functional cognitive decline and dementia. Though, there is substantial progress of medical science but still we required new strategies, new drug to combat the disease. ${ }^{27,28}$ This study was designed for 35 days and considered as method to evaluate nuerodegeration using same animals to reduce use/sacrifice of experimental animal considering good practice of 4 ' $R$ ' concept (replacement, reduction, refinement and rehabilitation), the various model was employed to evaluate memory, learning and anxiety during this period.

Lead acetate-induced neurodegenerative model used to study neurobehavioral changes and memory dysfunction. In this study, the effect of improving the memory deficit of NDDCT was evaluated using lead acetate induced neurodegeneration in rats by different behavioral and biochemical parameters.

EPM and MWM are used as behavioral models to screen the effect of drug on learning, memory and anxiety. TL recorded in EPM is marked as a key parameter for the evaluation of cognition ability. ${ }^{29,30}$ The reduction in retention latency is related to betterment of memory. Cholinergic system of the central nervous system found to plays a key role in cognitive function regulation. ${ }^{29}$

Administration of lead acetate results significantly increase in TL. NDDCT particularly in lower dose reduced TL prolongation caused by lead acetate. Observations indicated neuroprotective effect of
NDDCT that may be linked with its effect on the cholinergic system.

MWM test used to evaluate spatial learning and memory, which found to depend on the coordinated action of between neurotransmitter systems and various parts of the brain. In such the process, the important role of the cholinergic system in the central nervous system is well-established. ${ }^{31}$ To verify the effect of investigating drug on spatial learning MWM model was used. After administration of lead, experimental animals were taking longer time to find hidden stage that indicated towards impairment of memory during spatial task. Remarkable reduction of ELT was observed in animals administered with low dose of NDDCT that indicated towards significant improvement in cognitive performance.

Locomotor activity was also recorded with actophotometer to find changes caused by NDDCT that may influence locomotion during EPM and MWM. Though, the significant variation in locomotor activity was found in groups treated with low dose NDDCT in $34^{\text {th }}$ day. These observations indicated towards sedative effect or interference in locomotion during EPM and MWM model. Thus, TL in EPM and ETL in MWM were purely resulting from memory improvement. These results indicated that low dose of NDDCT can restore memory (long-term) in lead-induced impairment of memory and cognitive function.

Activity of acetylcholinesterase in brain was estimated to examine the effect of NDDCT on the cholinergic system. Free radical-induced oxidative stress considered as key underlying mechanism in the pathogenesis of $\mathrm{AD}^{32}$ In this study, lead administration causes a significant increase in the level of AChE that causes breakdown of acetylcholine, which is similar with previous investigations. NDDCT avert the increase in AChE activity. Results indicated the modulation of cholinergic activity.

A number of studies confirmed that impairment of memory and other behavioral activities are associated with oxidative damage in lead-induced neurodegeneration. Neuronal membranes consist of high proportion of long-chain polyunsaturated fatty acids and thus lipid peroxidation is considered as important sign of neurodegeneration. Brain was venerable to lipid peroxidation as the brain uses approximate $33 \%$ of the inspired oxygen. ${ }^{33,34}$ Proteins and lipids are the chief functional and structural part of cell membrane and also venerable to the oxidative damage. Widespread evidence presents on the lipid peroxidation and oxidation of protein that leads to damage of membrane integrity. This is a key aspect in the quickening of ageing and neurodegenerative disorders. 
In this experiment, lead acetate in experimental animals cause lipid peroxidation and decreased antioxidant defense. MDA and TBARS is the last product of lipid peroxidation and indicating towards oxidative stress. Lead acetate administration in rats causes lipid peroxidation as evidenced by the high level of MDA and TBARS. NDDCT administration causes reduction in MDA and TBARs levels, indicating towards the reduction in lipid peroxidation. GSH is a non-enzymatic endogenous antioxidant that considered as the first-line defense in the brain against oxidative stress. ${ }^{35,36} \mathrm{Co}$-administration of NDDCT in test group animals significantly enhances GSH levels, which was reduced after lead administration. SOD and CAT are the two most important antioxidant enzymes. SOD catalyses superoxide anions, a most reactive free radical that responsible for cell membranes and macromolecule damage. CAT detoxify hydrogen peroxide and convert it to water and oxygen.${ }^{35}$ Hydrogen peroxide endorses the generation of different oxygen reactive species that significantly contribute to oxidative stress leading to the pathogenesis of NDDS. ${ }^{35,36}$ Lead acetate cause significant decrease in SOD and CAT level. Treatment with NDDCT significantly increased the activities of SOD and CAT in experimental rats.

The various studies have shown the pleiotropic functions of TNF- $\alpha$ and have linked with different neurodegenerative disorders. This explains the signaling pathways induced by TNF- $\alpha$ by its two types of receptors such as (TNFR1 and TNFR2) and they provide different functions in different neurodegenerative processes. It has become clear that TNF- $\alpha$ may exert different actions in neurodegenerative disease, which includes neurodegenerative effects and neuroprotective effects, which shows to depend on its signaling pathway via either TNFR1 or TNFR2. The specific target of these receptors is a hopeful therapeutic strategy for a number of disorders. ${ }^{37}$ Lead acetate administration resulted increase level of TNF- $\alpha$, an enzyme accountable for neurons the degradation, which is similar with past investigations. NDDCT restored TNF- $\alpha$ activity a dose-dependently manner. These results recommend the cholinergic neurotransmission modulation and inhibition of cholinergic neuronal loss by NDDCT. Chronic administration of lead acetate, in our study, elevates the degree of neuronal losses in the brain of experimental rats that were correlated with the reduction in serum nitrite/nitrate levels and increase in serum lead concentration. This elevation rate significantly managed and restored by NDDCT.

The results of this study suggested that NDDCT treatment particularly low dose produced significant improvement in memory, cognitive and behavioral tasks.
NDDCT found to upregulate endogenous antioxidants and exerted neuroprotective effect against free radicalinduced oxidative damage caused by lead acetate. A lower dose of NDDCT, i.e., $5 \mathrm{mg} / \mathrm{kg}$, p.o. exerted better neuroprotective effect in majority of behavioral and biochemical evaluations that was also confirmed in histopathological studies. AChE inhibition and antioxidant are considered as key mechanism through which NDDCT exerted neuroprotective effects.

\section{CONCLUSION}

Lead acetate induced Alzheimer's type of dementia is primarily linked with impairment of cognitive and memory in behavioral models. NDDCT improved the levels of endogenous antioxidants, reduce oxidative stress, inhibit AChE and positively ameliorate biochemical parameters (such as serum lead concentration, nitrite and $\mathrm{TNF}-\alpha$ level) that may responsible for its protective effect against lead induced neurodegeneration. Present study indicated that NDDCT have the potential to impede cholinergic dysfunctions and oxidative stress. Further study is required to find exact mechanism and effect of NDDCT on the major biomarkers of neurodegeneration.

\section{ACKNOWLEDGEMENT}

Authors are thankful to the Principal and Management of Hygia Institute of Pharmaceutical Education and Research, Lucknow, Uttar Pradesh, India for proving necessary permission and infrastructure to carry out the experiment.

\section{CONFLICT OF INTEREST}

The authors declare no conflict of interests.

\section{ABBREVIATIONS}

NDDCT: Natrium diethyl dithiocarbamate trihydrate; NF- $\boldsymbol{x B}$ : Nuclear factor kappa-B; MWM: Morris water maze; ELT: Escape latency time; EPM: Elevated plus maze; TL: Transfer Latency; AChE: Acetylcholinesterase; NO: Nitric oxide; SOD: Superoxide dismutase; CAT: Catalase; GSH: Reduced Glutathione; TBARS: Thiobarbituricacid reactive substances; MDA: Malondialdehyde.

\section{REFERENCES}

1. Ramanan VK, Saykin AJ. Pathways to neurodegeneration: Mechanistic insights from GWAS in Alzheimer's disease, Parkinson's disease and related disorders. Am J Neurodegener Dis. 2013;2(3):145-75. 
2. Ashraf GMD, Greig NH, Khan TA, Hassan I, Tabrez S, Shakil S. Protein misfolding and aggregation in Alzheimer's disease and type 2 diabetes mellitus. CNS Neurol Disord Drug Target. 2014;13(7):1280-93.

3. Bertram L, Tanzi RE. The genetic epidemiology of the neurodegenerative disease. J Clin Invest. 2005;115(6):1449-57.

4. Samini F, Borji A. Lead exposure and neurodegenerative diseases. Der Pharmacia Lettre. 2016;8(8):14-8.

5. Mason LH, Harp JP, Han DY. Pb neurotoxicity: Neuropsychological effects of lead toxicity. Biomed Res Int. 2014;1-8.

6. Sharma A, Maurya $\mathrm{H}$. An update on sodium diethyldithiocarbamate trihydrate The Pharm Chem J. 2018;5(5):143-9.

7. Sharma B, Singh N. Defensive effect of natrium diethyldithiocarbamate trihydrate (NDDCT) and lisinopril in DOCA-salt hypertension-induced vascular dementia in rats. Psychopharmacol. 2012;223(3):307-17.

8. Sharma D, Puri M, Tiwary AK, Singh N, Jaggi AS. Antiamnesic effect of stevioside in scopolamine-treated rats. Indian J Pharmacol. 2010;42(3):1647.

9. Sharma M, Gupta YK. Intracerebroventricular injection of streptozotocin in rats produces both oxidative stress in the brain and cognitive impairment. Life Sci. 2001;68(9):1021-9.

10. Kaur R, Mehan S, Khanna D, Kalra S. Ameliorative treatment with ellagic acid in scopolamine-induced Alzheimer's type memory and cognitive dysfunctions in rats. Austin J Clin Neurol. 2015;2(6):1053-62.

11. Qu C, Lu D, Goussev A, Schallert T, Mahmood A, Chopp M. Effect of atorvastatin on spatial memory, neuronal survival and vascular density in female rats after traumatic brain injury. J Neurosurg. 2005;103(4):695-701.

12. Nambiar RP, Chowta MN, Nishith RS, Priyanka K, Hadigal S. Evaluation of the effect of Atrovastatin on learning and memory in Wistar rats. Int J Pharm. 2015;5(2):408-12.

13. Kumar A, Dogra S, Prakash A. Neuroprotective Effects of Centella asiatica against Intracerebroventricularcolchicine-induced cognitive impairment and oxidative stress. Int J Alzheimers Dis. 2009;2-8.

14. Bharti K, Majeed ABA, Prakash A. Possible role of metal ionophore against zinc-induced cognitive dysfunction in d-galactose senescent mice. Biometals. 2016;29(3):399-409

15. Sastry KV, Moudgal RP, Mohan J, Tyagi JS, Rao GS. Spectrophotometric determination of serum nitrite and nitrate by copper-cadmium alloy. Anal Biochem. 2002;306(1):79-82.

16. Sharma B, Singh N. Pitavastatin and 4'-hydroxy-3'-methoxyace acetophenone HMAP reduce cognitive dysfunction in vascular dementia during experimental diabetes. Curr Neurovasc Res. 2010;7(3):180-91.

17. Wills ED. Mechanism of lipid peroxide formation in animal tissues. Biochem. 1966;99(3):667-76.

18. Veiopoulou CJ, Lianidou ES, Ioannou PC, Efstathiou CE. Comparative study of fluorescent terbium complexes. Application in enzyme amplified fluorimetric immunoassay for a-fetoprotein. Analytica Chimica Acta. 1996;335(1-2):17784

19. Ellman GL, Courtney DK, Andres V, Feathstone RM. A new and rapid colorimetric determination of acetylcholinesterase activity. Biochem Pharmacol. 1961;7(2):88-95.

\section{PICTORIAL ABSTRACT}

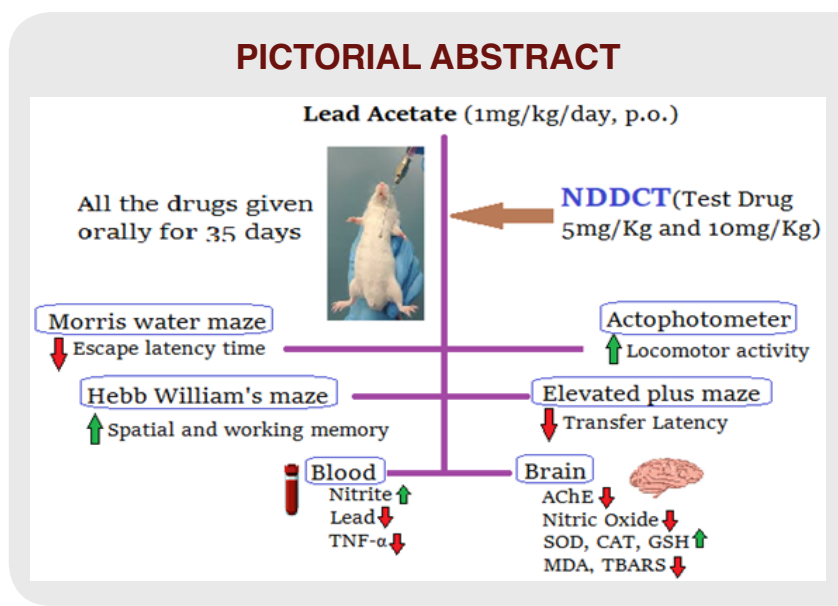

20. Miranda KM, Espey MG, Wink DA. A rapid, simple spectrophotometric method for simultaneous detection of nitrate and nitrite. Nitric Oxide. 2001;5(1):62-71.

21. Zaki HF, Fattah MAAE, Attia AS. Naringenin protects against scopolamineinduced dementia in rats. Bull Fac Pharm Cairo Univ. 2014;52(1):15-25.

22. Misra HP, Fridovich I. The role of superoxide anion in the autoxidation of epinephrine and a simple assay for superoxide dismutase. J Biol Chem. 1972;247(10):3170-5.

23. Aebi H, Wyss SR, Scherz B, Skvaril F. Heterogeneity of erythrocyte catalase II. Isolation and characterization of normal and variant erythrocyte catalase and their subunits. Eur J Biochem 1974;48(1):137-45.

24. Beutler E, Duron O, Kelly B. Improved method for the determination of blood glutathione. JLB Clinical Med. 1963;61:882-8.

25. Ohkawa $\mathrm{H}$, Ohishi $\mathrm{N}$, Yagi K. Assay for lipid peroxides in animal tissues by thiobarbituric acid reaction. Anal Biochem. 1979;95(2):351-8.

26. Stephenson DT, Neill SMO, Narayan S, Tiwari A, Arnold E, Samaroo HD, et al. Histopathologic characterization of the BTBR mouse model of autistic-like behavior reveals selective changes in neurodevelopmental proteins and adult hippocampal neurogenesis. Mol Autism. 2011;2(1):7-21.

27. Bhushan I, Kour M, Kour G, Gupta S, Sharma S, Yadav A. Alzheimer's disease: Causes and treatment: A review. Ann Biotechnol. 2018;1(1):100210.

28. Gitler AD, Dhillon P, Shorter J. Neurodegenerative disease: Models, mechanisms and a new hope. Dis Model Mech. 2017;10:499-502.

29. Dhingra D, Kumar V. Memory-enhancing activity of palmatine in mice using elevated plus maze and morris water maze. Adv Pharmacol Sci. 2012;35768.

30. Khatian N, Aslam M. Effect of Ganoderma lucidum on memory and learning in mice. Clinical Phytoscience. 2019;5(4):4.

31. Hosseini-Sharifabad A, Mohammadi-Eraghi S, Tabrizian K, Soodi M, Khorshidahmad T, Naghdi N, et al. Effects of training in the Morris water maze on the spatial learning acquisition and VAChT expression in male rats. Daru. 2011;19(2):166-72.

32. Kulshreshtha A, Piplani P. Current pharmacotherapy and putative diseasemodifying therapy for Alzheimer's disease. Neurol Sci. 2016;37(9):1403-35.

33. Gella A, Durany N. Oxidative stress in Alzheimer disease. Cell Adh Migr 2009;3(1):88-93

34. Balu M, Sangeetha P, Haripriya D, Panneerselvam C. Rejuvenation of antioxidant system in the central nervous system of aged rats by grape seed extract. Neurosci Lett. 2005;383(3):295-300.

35. Lobo V, Patil A, Phatak A, Chandra N. Free radicals, antioxidants and functional foods: Impact on human health. Pharmacogn Rev. 2010;4(8):11826.

36. Uttara B, Singh AV, Zamboni P, Mahajan RT. Oxidative stress and neurodegenerative diseases: A review of upstream and downstream antioxidant therapeutic options. Curr Neuropharmacol. 2009;7(1):65-74.

37. Dong Y, Dekens DW, Deyn PPD, Naude PJW, Eisel ULM. Targeting of tumor necrosis factor alpha receptors as a therapeutic strategy for neurodegenerative disorders. Antibodies. 2015;4(4):369-408.

\section{SUMMARY}

Treatment with NDDCT found effective to prevent neurodegeneration induced by lead acetate. NDDCT found to improve escape latency time, transfer latency time, spatial and working memory locomotor activity. Neuroprotective activity of NDDCT was confirmed by evaluation of in vivo antioxidant activity and estimation of other biochemical parameters like I serum lead, TNF- $\alpha$, nitric oxide, acetylcholinesterase enzyme. 


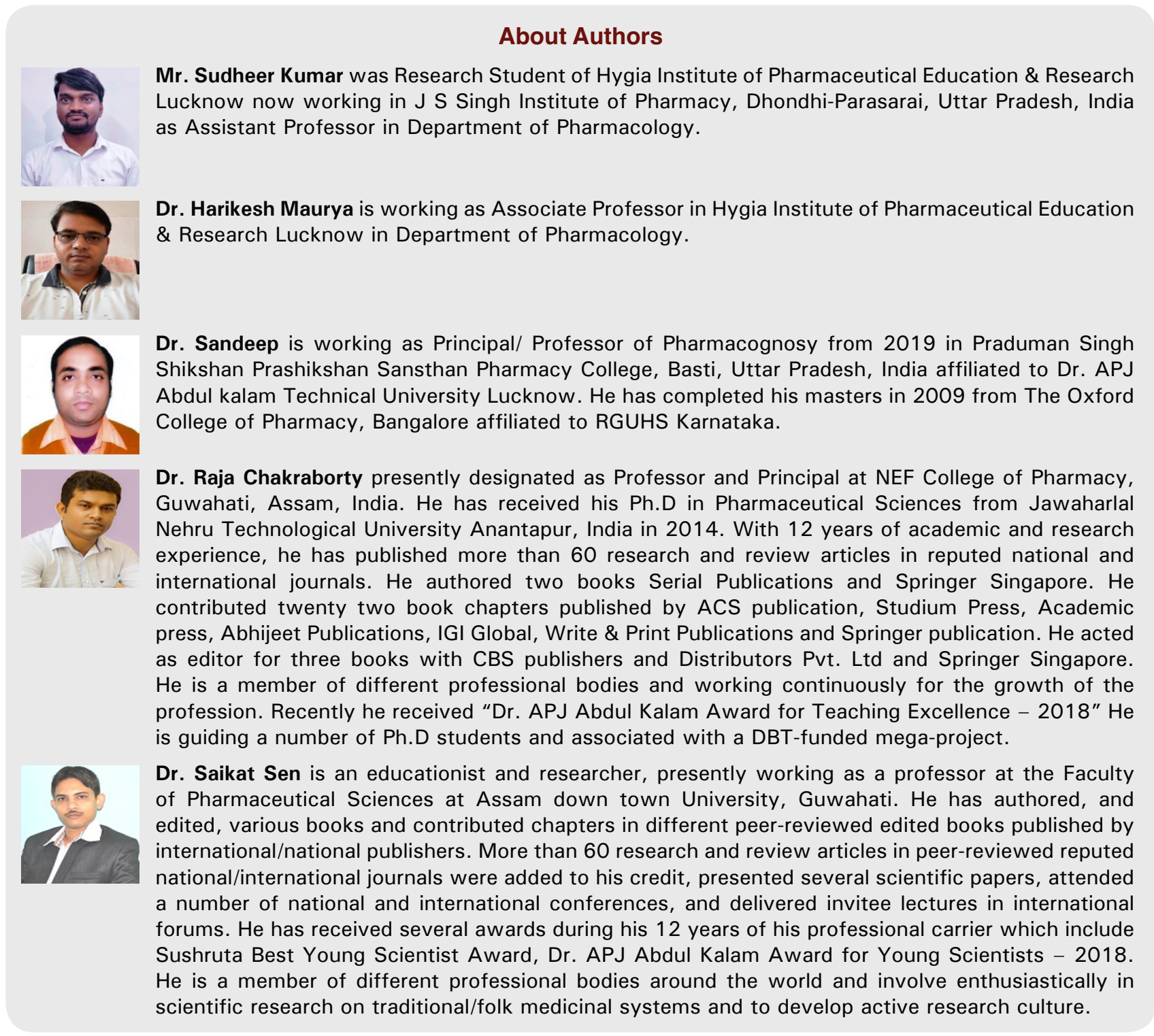

Cite this article: Kumar S, Maurya H, Sandeep, Sen S, Chakraborty R. Protective Effect of Natrium Diethyldithiocarbamate Trihydrate (NDDCT) on Lead induced Neurodegeneration in Rats. Indian J of Pharmaceutical Education and Research. 2021;55(1):126-35. 